\title{
Land-use change arising from rural land exchange: an agent-based simulation model
}

\author{
Martha M. Bakker · Shah Jamal Alam • \\ Jerry van Dijk · Mark D. A. Rounsevell
}

Received: 13 January 2014/Accepted: 2 November 2014/Published online: 15 November 2014

(C) The Author(s) 2014. This article is published with open access at Springerlink.com

\begin{abstract}
Introduction Land exchange can be a major factor driving land-use change in regions with high pressure on land, but is generally not incorporated in land-use change models. Here we present an agent-based model to simulate land-use change arising from land exchange between multiple agent types representing farmers, nature organizations, and estate owners.

Methods The RULEX model (Rural Land EXchange) was calibrated and applied to a $300 \mathrm{~km}^{2}$ case study area in the east of the Netherlands. Decision rules about which actor will sell and buy land, as well as which specific land to buy or sell are based on historical observations, interviews, and choice experiments.
\end{abstract}

Electronic supplementary material The online version of this article (doi:10.1007/s10980-014-0116-x) contains supplementary material, which is available to authorized users.

M. M. Bakker ( $\square)$

Land Use Planning Group, Wageningen University, Droevendaalsesteeg 3, 6708 PB Wageningen,

The Netherlands

e-mail: martha.bakker@wur.nl

\section{S. J. Alam · M. D. A. Rounsevell}

School of GeoSciences, University of Edinburgh,

Drummond Street, Edinburgh EH8 9XP, UK

J. van Dijk

Copernicus Institute of Sustainable Development, Utrecht University, Heidelberglaan 2, 3584 CS Utrecht,

The Netherlands
Results A reconstruction of land-use change for the period 2001-2009 demonstrates that RULEX reproduces most observed land-use trends and patterns. Given that RULEX simulates only one mechanism of land-use change, i.e. land exchange, it is conservative in simulating change.

Conclusions With this model, we demonstrate the potential of incorporating land market processes in an agent-based, land-use change model. This supports understanding of land-use change that is brought about by ownership change, which is an important process in areas where pressure on land is high. The soundness of the process representation was corroborated by stakeholders within the study area. Land exchange models can be used to assess the impact of changes in climate, markets, and policy on land use change, and help to increase effectiveness of alternative land purchasing strategies by stakeholders or spatial planning policy.

Keywords Agent-based modelling · Land-use change $\cdot$ Nature restoration $\cdot$ Farmer decision-making · Ownership structures $\cdot$ Spatial planning

\section{Introduction}

Agent-based models (ABMs) are used increasingly to simulate rural land-use change (Berger 2001; Valbuena et al. 2010). Compared to the more traditional pattern-mimicking models (Hilferink and Rietveld 1998; Verburg and Overmars 2009) and bio-economic 
optimization models (van Ittersum et al. 2008), ABMs are better able to represent the diversity of decisionmaking strategies that underpin land-use change (Bousquet and Le Page 2004; Parker et al. 2008; Polhill et al. 2011). Some ABMs focus on interactions between agents, such as imitation and the spread of knowledge or information (Berger 2001; Macmillan and Huang 2008; Alexander et al. 2013), whilst others focus on the diversity amongst agents in terms of alternative motives and strategies (Karali et al. 2011; Kelley and Evans 2011). Whilst agents in models of urban dynamics are generally mobile (Xie et al. 2007; Brown et al. 2008; Huang et al. 2013), a common feature of ABMs used to simulate rural dynamics is the immutable location of the land-user agent in geographic space, and the limited range of agent roles with a common focus on farmers. In such models, land-use change results when a farmer agent changes the way it uses the land, while the delineation of the agent's property remains fixed. Few ABMs simulate rural land-use change as the result of land exchange between agents, involving the reallocation of property ownership (Filatova et al. 2011; Schouten et al. 2013). The fixed-property approach seems appropriate when modelling, for example, relatively small changes in management or the adoption of an innovation. We expect, however, that categorical land-use change, such as the conversion from arable farming to livestock farming or from farming to nature conservation, will arise also from land exchange from one agent type to another. This is because a categorical change often requires considerable investment in knowledge and equipment for most land owners (Rounsevell et al. 2003), while it may also lead to undesired social effects such as an alienation from one's network of peers (Karali et al. 2013a, b), which have been shown to strongly influence the willingness to change (Lokhorst et al. 2010, 2011). This is supported by data from the Dutch Agricultural Economics Institute, which demonstrate that-over a time span of 10 years-farms that undergo a categorical land-use change (e.g., from dairy farming to arable farming) cover about $4 \%$ of the total agricultural area, while parcels that undergo such a change (i.e. from being owned by e.g. a dairy farmer to being owned by an arable farmer) cover about $11 \%$ (Dienst Regelingen; Government Service for Land and Water Management, 2012). If categorical land-use change were brought about only by farmers changing from one land use to the other, the number of parcels that underwent a categorical change should also have been about $4 \%$ (assuming that changing farms have approximately the same number of parcels as other farms). The fact that the change rate of parcels is higher, suggests that for about $7 \%$ of all parcels, land-use change is the result of parcels being sold from one type of farmer to the other. Hence, more than half of the observed landuse change in the Netherlands appears to result from land exchange. Thus, we argue that to effectively simulate categorical land-use change it is necessary to simulate rural land exchange. In this paper we present the development and application of an ABM that simulates land use change as a result of land exchange in rural areas.

The RULEX model (RUral Land EXchange model) simulates land-use change arising from land exchange between different types of land owners in intensively used rural areas. The model was developed for, and tested in, a case study region of about $300 \mathrm{~km}^{2}$ in the east of the Netherlands. Parts of the region have been designated within the Dutch National Ecological Network, and for this reason the provincial government provides financial and organizational support for the acquisition and subsequent conversion of agricultural land to nature. Nature, in this case, refers to the restoration of (semi-) natural habitats (e.g., forest, heathland, and wetland) on what was previously agricultural land. Private estate owners also expand their estates by buying adjacent agricultural land. Hence, the main land claims in this region are from farmers, nature organizations, and private estate owners which are therefore the three types of agents represented in RULEX. The land use types that are distinguished are arable farming, dairying, horticulture, pig-breeding, mixed farming, nature owned by estate owners, and nature owned by nature organizations.

Both the conversion of land from agriculture to nature by means of land exchange between nature organizations, estate owners, and farmers as well as the exchange of land between different agricultural sectors are key processes that lead to land-use change in the region. This raises policy-relevant questions such as: which agricultural sector will grow, which will shrink and where; will farms continue to grow (in land area terms) and is this location-specific; and, why do we observe that the conversion of farmland to nature is slowing down, and will this trend continue 
into the future? These issues can be encapsulated into a single overarching purpose for developing the RULEX model, which is to understand how land exchange among farmers and between farmers, estate owners, and nature organizations affects rural land-use patterns.

In this paper, we demonstrate how processes of land exchange can be captured and formalized in rules and equations. Including land exchange between different categories of farmers, as well as between farmers and other types of land users, is challenging because the various agents within the land market have different criteria with respect to land value and other financial and legal positions that require different types of data evidence (Geller and Moss 2008). This may also explain why many contemporary land exchange models do not model categorical land-use change since they are limited to rather homogeneous populations of agents (Matthews et al. 2007). We start by describing the case study area and the data that was used in the model development and calibration. Next, we present the general design of the RULEX model, including the calibrated settings, rules and equations. Parameters that could not be obtained from observational data were obtained by calibrating RULEX on land transaction data from 2001 to 2009 . We assess the model's performance by comparing observed and simulated land use, and conclude with a discussion about the model's strengths and weaknesses and potential applications.

\section{Study area and data}

\section{Study area}

The RULEX model was calibrated for, and applied to, an area in the East of the Netherlands (Fig. 1), delineated by the stream valley of the "Baakse Beek" (beek is Dutch for brook), and known as the Baakse Beek area. The area is roughly $10 \mathrm{~km}$ from north to south and $30 \mathrm{~km}$ from east to west. Since the establishment of the EU's Common Agricultural Policy, the area underwent a transition from mixed farming to specialized farming (mostly intensive dairying) and farm sizes increased considerably in order to benefit from economies of scale. Current-day agriculture is typical of areas in Western Europe with high population pressure leading to intensive farming that is highly efficient from an economic perspective. Despite this, the area is still considered to be a visually attractive, small-scale landscape. Hedgerows, which are conserved by law, and the presence of large numbers of estates and nature reserves contribute to this image. For this reason, tourism forms an important part of the regional economy, and policymakers are concerned with maintaining the traditional character of the landscape. Over the last 20 years, nature restoration has become important in the area. The National Ecological Network (NEN), defined by zoning policies in the 1990s, covers a considerable part of the area (3,804 ha, about $12.7 \%$ of the area, of which 2,769 ha has currently been realized). All agricultural land within this zone is intended to be converted to nature. Land exchange between farmers and nature organizations in achieving this network has been on a voluntary basis, and nature organizations were required legally to pay agricultural market prices for agricultural parcels.

The Baakse Beek contained approximately 1,320 land-owning farmers in 2001, which is the initial year of the simulations. About 481 farmers had parcels within the area, but farmsteads that were located outside of the area. These farmers are registered in the agricultural census, which excludes hobby farmers and other farms with an economic size smaller than three NGE (Dutch farm size units). Distributions of the characteristics of the farm(er)s in the Baakse Beek are given in Fig. 2. The area comprised 5,877 (registered) parcels. ${ }^{1}$ A summary of the parcel properties is given in Table 1.

Nature organizations that are active in the area are Natuurmonumenten (a private foundation for nature conservation), the State Forestry Service (an independent governmental organization for forestry and nature conservation), Geldersch Landschap \& Kasteelen (a private foundation for the conservation of natural and cultural heritage), and 87 private estates. In the Baakse Beek, these organizations owned approximately $176,733,50$, and 1,788 hectares respectively in 2001 .

\footnotetext{
1 There were fewer parcels in the database than in reality, as not all parcels were registered in 2001. It has been estimated that the database contains about $80 \%$ of the existing parcels (T. Kuhlman, Agricultural Economics Institute, pers comm).
} 
Fig. 1 The Baakse Beek area with land use of 2001

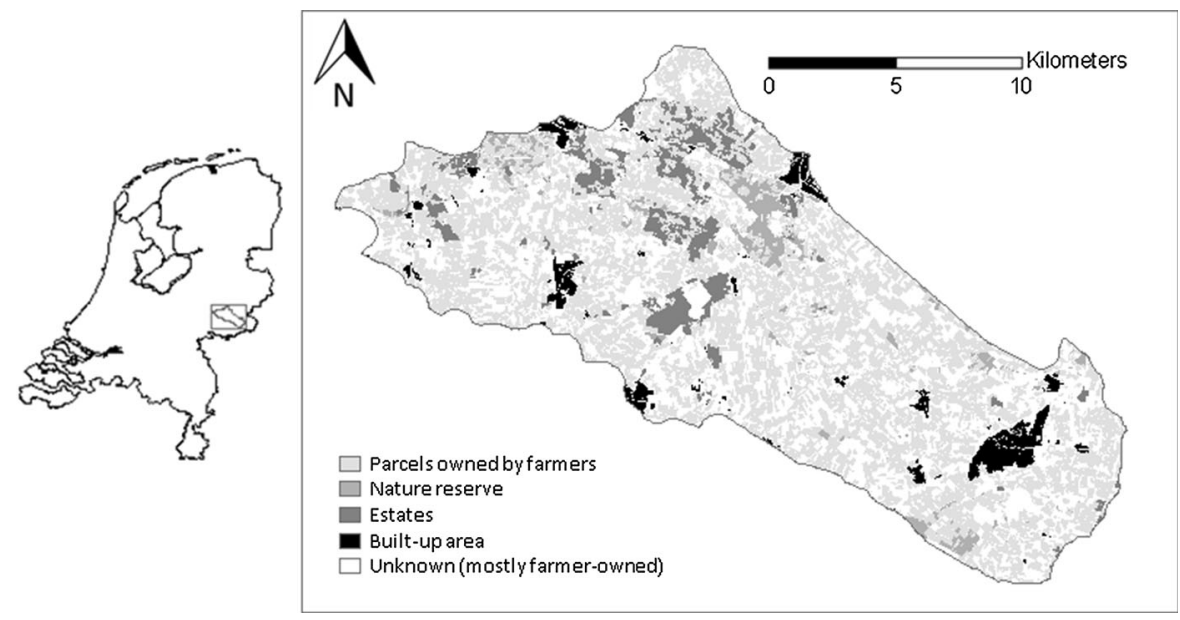

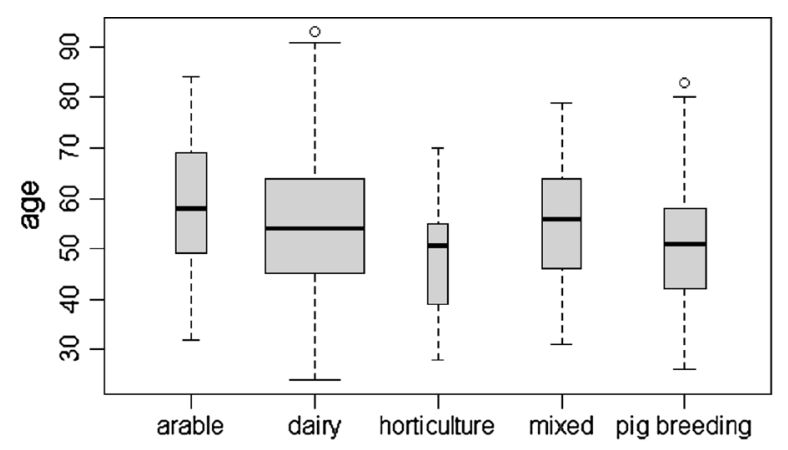
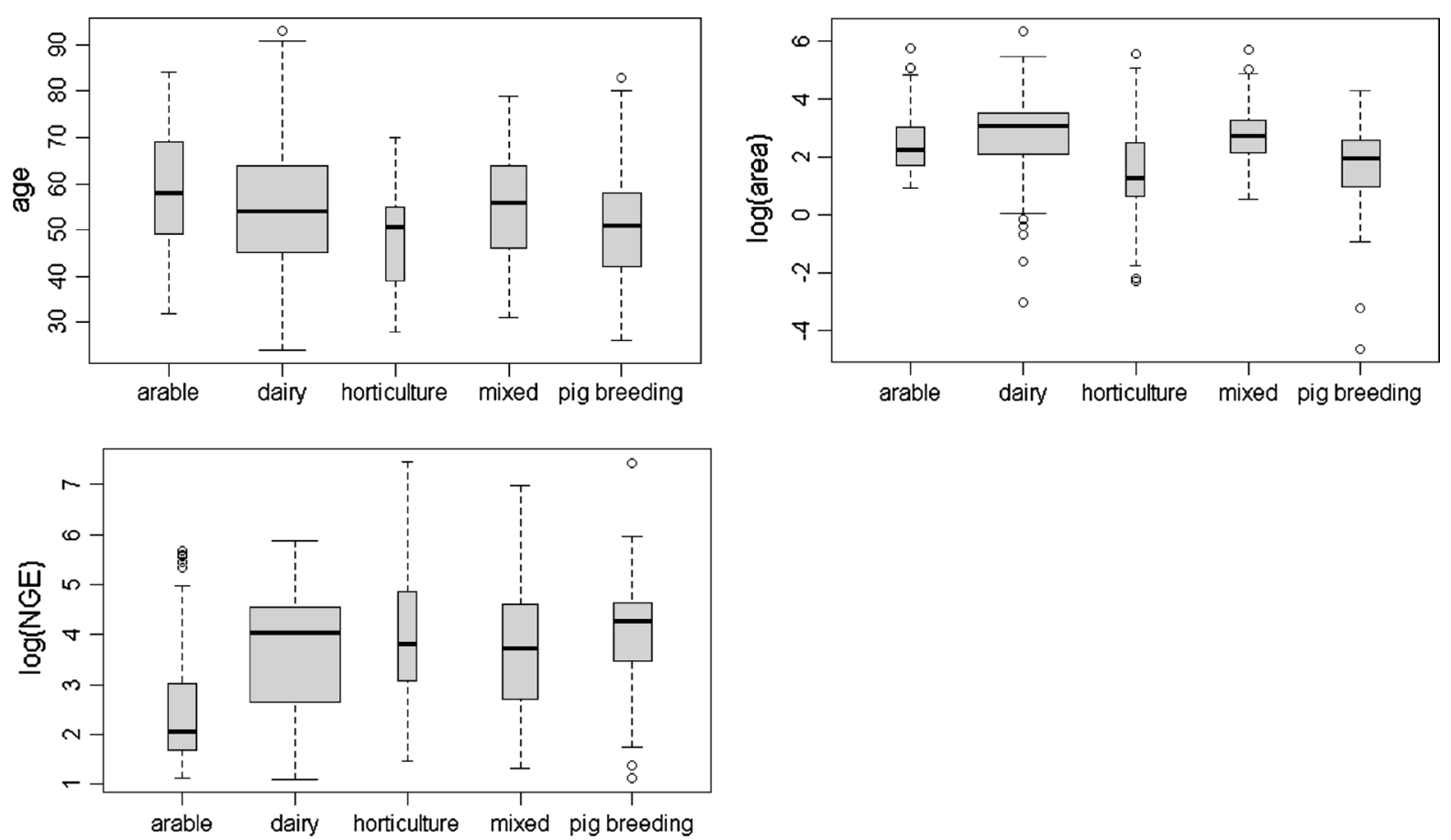

Fig. 2 Box-and-whisker plots for farm(er) characteristics for the Baakse Beek area per farming type. Derived from agricultural census data of 2001. From top in clockwise direction: age, physical size (ha) in log scale, and economic size (NGE) in log scale

Data

The following data were available for calibrating model rules, equations, and settings:

- Agricultural census data, containing economic size, physical size, farmer age and farming type for each farm. We used data from 1999, 2001 and 2009. The data for 2001 were used to set-up the initial model year. Not all records were complete so farms without data were randomly assigned representative properties in line with the available data for other farms. Where farm locations were unavailable, we assume a location outside of the Baakse Beek area and assigned random coordinates from outside of the region (Alam et al. 2014). A unique identifier linked each parcel to its owner, 
Table 1 Summary statistics of land parcel characteristics in the Baakse Beek area for the year 2001

\begin{tabular}{llll}
\hline Land parcel characteristics & Mean & Median & Range \\
\hline Size (hectares) & 2.5 & 1.8 & $0.02-25.2$ \\
Soil suitability (index) & 82 & 82.5 & $0-100$ \\
$\begin{array}{l}\text { Distance to village (meters) } \\
\text { Distance to NEN (meters) }\end{array}$ & 2,702 & 2,577 & $0-6,723$ \\
$\begin{array}{l}\text { Distance to existing nature } \\
\text { reserves (meters) }\end{array}$ & 837 & 203 & $0-2,930$ \\
$\begin{array}{l}\text { Presence of seepage } \\
\quad \text { present = 1; absent =2) }\end{array}$ & 1.8 & 1.8 & 1,2 \\
$\begin{array}{l}\text { Average spring groundwater } \\
\text { level (meters below surface) }\end{array}$ & 0.7 & 0.8 & $0-3,824$ \\
\hline
\end{tabular}

so that farm data could be linked to spatial parcel data (ArcGIS shapefiles), which were available for 2001 and 2009.

- Records of rural land exchange [Infogroma, (DLG 2012)], including price paid, identity of seller and buyer, and the location of the sold parcels. Using ArcMAP10 the locations of the sold parcels were related to the parcel database and a set of auxiliary data. This allowed us to identify, for each exchange transaction, data on parcel size, soil properties, distance to major roads, villages and nature reserves, being situated inside or outside the areas designated for the NEN, and the distance to this network. These data were used to calibrate parcel evaluation by agents. Furthermore, data on the total number of farmer-farmer land exchange transactions and the total number of farmer-nature land exchange transactions were derived from this database, which were used to fine-tune the model. ${ }^{2}$

- We used a combination of explorative interviews and conjoint analysis to inform RULEX about parcel evaluation by nature agents and estate owners. Explorative interviews were conducted with seven local representatives at strategic management positions within each of the nature organizations and a lobby organization for estate owners. Additionally, we asked six representatives of two different nature organizations, who were all involved in parcel evaluation before acquisition, to

\footnotetext{
${ }^{2}$ Note that assessing transaction quantities could not be done very accurately, as intermediate parties (mostly a governmental institute serving as a 'land bank') and parties identified as 'private persons' (as opposed to farmers or nature organizations) introduced uncertainty.
}

rank fictional parcels from high to low preference. These data were used to calibrate the parcel evaluation by nature agents. All interviews were conducted in 2011. The conjoint analysis was performed in 2013.

- Finally, additional data came from ancillary sources: price changes in the period 2001-2009 from the Agricultural Economics Institute databases; the rate of farm succession in the Netherlands from the Agricultural Economics Institute reports; and life expectancy tables from reports of the WHO.

We used the following available data to evaluate the performance of the model:

- A map of observed land-use in 2009. This map was used in three ways: (1) to compare simulated land use trends with observed trends; (2) to compare a cross table of observed land use in 2001 and simulated land use in 2009 with a cross table of observed land use in 2001 and observed land use in 2009 (i.e. conversion-specific change); and (3) by making an overlay of the simulated and observed land use maps, which was classified into (a) observed change simulated correctly as change (i.e., hits), (b) observed change simulated incorrectly as persistence (i.e., misses); (c) observed persistence simulated incorrectly as change (i.e., false alarms); (d) observed persistence simulated correctly as persistence (i.e., correct rejections); and (e) observed change simulated incorrectly as change to the wrong gaining category (i.e., wrong hits) (Brown et al. 2013a). Because of missing data in the agricultural censuses of both years, the area for which both years have complete records covers $83 \%$. Also, data on the area that belonged to a nature organization or estate owner in 2001 was missing, and had to be inferred from their property in 2009, by subtracting the parcels that belonged to farmers in 2001. Maps of land use in 2001 and 2009 can be found in the online supplement (Fig. s1).

\section{Model description}

Here we describe RULEX in a quasi-ODD format (Grimm et al. 2006). Table 2 presents the characteristics of the model and its entities. We present 
Table 2 Description of model characteristics and entities

\begin{tabular}{|c|c|}
\hline Model element & Description \\
\hline Temporal units & Each time step in the model represents 1 year in reality \\
\hline Spatial units & Parcels (polygon shapefile) \\
\hline Farmer agents & $\begin{array}{l}\text { Agents representing farmers present in the simulated area. They are described by their age, and are } \\
\text { one-to-one linked to a farm. Data for the base year is obtained from the agricultural census }\end{array}$ \\
\hline Farms & $\begin{array}{l}\text { Each farm belongs to one farmer agent. Farms have a farmstead with a location (point shapefile) and } \\
\text { are described by farming type (e.g., dairy, arable), economic size, physical size, and a Boolean } \\
\text { variable indicating whether or not the farm has grown by more than } 4 \text { hectares over the } 10 \text {-year } \\
\text { period preceding the baseline year. Data for the base year is obtained from the agricultural census. } \\
\text { Because of the one-to-one link with farmers, we use the terms farms and farmers interchangeably in } \\
\text { this paper }\end{array}$ \\
\hline Parcels & $\begin{array}{l}\text { Each parcel belongs to a farmer agent who may have one or more parcels any time during simulation. } \\
\text { Parcels have a spatial extent and location (polygon shapefile) and are described by the following } \\
\text { properties: agricultural soil suitability, levels of seepage, soil type, distance to the National } \\
\text { Ecological Network, and distance to the nearest town/village }\end{array}$ \\
\hline Nature-organization agents & $\begin{array}{l}\text { Nature-organization agents represent existing nature organizations that are active in the area. They are } \\
\text { described by the way they evaluate for-sale parcels }\end{array}$ \\
\hline Nature areas & $\begin{array}{l}\text { Nature areas are described by a polygon shapefile, with the name of the owning nature organization as } \\
\text { the only attribute }\end{array}$ \\
\hline Estate-owner agents & $\begin{array}{l}\text { Estate-owner agents represent owners of estates in the area. They are described by an ID and by the } \\
\text { way they evaluate for-sale parcels }\end{array}$ \\
\hline Estates & Estates are described by a polygon shapefile, with the ID of the estate owner as the only attribute \\
\hline Behaviours or strategies & $\begin{array}{l}\text { An attribute assigned to each agent, each model year. For farmer agents these can be expanding, } \\
\text { shrinking, intensifying/innovating, or stable. These behaviours are derived from the farm(er)s' } \\
\text { characteristics (age, type, economic and physical size, and expanding behaviour in the previous } \\
10 \text {-year period); the behaviour of nature agents and estate agents is set to be expanding }\end{array}$ \\
\hline Extent of application & $\begin{array}{l}\text { The model is applied to an area of approximately } 30 \times 10 \mathrm{~km} \text { and the calibration period is from } 2001 \\
\text { to } 2009 \text {, with } 2001 \text { referred to here as the base year }\end{array}$ \\
\hline External drivers & $\begin{array}{l}\text { Changes in economic markets and policies are translated into trends in economic farm-size at sector } \\
\text { level. Potentially, other external drivers can be introduced, for instance by climate change affecting } \\
\text { the hydrology: a parcel property which affects the various agents' willingness to pay }\end{array}$ \\
\hline Model inputs & $\begin{array}{l}\text { Tabular data of parcel characteristics and farmer characteristics of base year; Shapefiles of parcels, } \\
\text { farms, estates, and nature areas. Trends in economic farm size per sector. Optional for exploring } \\
\text { scenarios: trends in soil suitability (parcel characteristic) }\end{array}$ \\
\hline Model settings & $\begin{array}{l}\text { Coefficients that determine the probability distribution of farmer behaviour, coefficients that determine } \\
\text { parcel evaluation (one set for farmers, one for nature organizations, and one for estate owners), } \\
\text { farmers' retirement age, threshold in economic size for finding a successor, rate by which the } \\
\text { economic farm size of intensifier agents grows }\end{array}$ \\
\hline
\end{tabular}

calibrated rules, equations or settings, most of which refer to the online supplement for details. The online supplement contains a pseudo code of this procedure (Fig. s4), as well as a UML Activity diagram (Fig. s5).

\section{Model aim}

The aim is to understand how land exchange between farmers, estate owners, and nature organizations shape rural land-use patterns.
Agents

Agents in the model represent farmers, nature organizations, and estate owners. Farmer agents have attributes describing their age, the type of farming practiced (viz. arable farmers, dairy farmers etc.), the economic and physical farm size, and whether or not the farm expanded by more than four hectares during the preceding 10-year period. Each farm is linked to a number of parcels in the parcel shapefile. Nature 
agents represent nature organizations that are active in the land market in the case study region. They are described by the way they evaluate for-sale parcels and their land ownership in the base year. Likewise, estates were modelled as a single entity (comparable to a nature organization), and are described by the way they evaluate for-sale parcels and their land ownership in the base year. These three types of agents differ fundamentally (i.e., they have different motives and aims) as well as structurally (i.e., many individuals versus a few organizations) and hence require a different modelling and calibration approach.

\section{Behaviour of farmer agents}

The following behaviours of farmer agents are distinguished: expanding (to benefit from economies of scale) and shrinking (to enhance liquidity in support of the continuation of the farm). The 'expanders' try to buy land, while the 'shrinkers' try to sell land. Farmer agents that do not participate in the land market may intensify or innovate (i.e. increase economic size while physical size stays constant) or they may do nothing. (Although intensifying/innovating does not lead to land exchange directly, it may affect the farmer agent's tendency to expand or shrink at a later time step.) The four behaviours were derived from a combination of exploring the empirical census data, from discussion with local stakeholders, and from the logical thought process that land transactions must involve buyers (i.e. expanders) and sellers (i.e. shrinkers). This is a new approach to modelling land use change that focuses on land market transactions. These behaviours are considered to be a function of the farm(er)'s attributes age, farming type, economic size, and physical size. ${ }^{3}$ This function takes the form of a logistic probability equation that allows an estimation of which of the four behaviours each individual farmer is allocated.

\footnotetext{
$\overline{3}$ Other variables were available in the census data, of which some may be good predictors of buying and selling behaviour (e.g. hours spent on farming, income derived from off-farm work, and for some years even the presence of a successor was reported). However, we limited ourselves to those factors which we could meaningfully update throughout a model simulation run, i.e. that change because of land exchange (economic and physical size) or which are otherwise fairly predictable (age).
}

The probability of a farmer displaying behaviour type $\mathrm{k}=1-4$ is:

$$
P(\text { behaviour }=k)=\frac{e^{\operatorname{LOGIT}(k)}}{1+\sum_{k=1}^{4} e^{\operatorname{LOGIT}(k)}}
$$

With:

$$
\begin{aligned}
& \text { LOGIT }(\text { expander })=-2.96-0.02 \text { Age } \\
& \quad-0.01 \log (\text { Area })+0.75 \log (N G E)+0.61 \\
& \text { PrevExp }+0.79(\text { Dairy } * \log (N G E))
\end{aligned}
$$

\section{LOGIT(intensifier/innovator)}

$$
\begin{aligned}
& =-1.40-0.03 \text { Age }-0.40 \log (\text { Area }) \\
& \quad+0.42 \log (N G E)+0.80 \text { PrevExp } \\
& \quad-0.58(\text { Dairy } * \log (N G E)) \\
& \text { LOGIT }(\text { shrinker })=-3.47+0.02 \text { Age } \\
& \quad+0.96 \log (\text { Area })-0.43 \log (N G E)+0.23 \\
& \quad \text { PrevExp }-0.25(\text { Dairy } * \log (N G E))
\end{aligned}
$$

With Age being the age of the farmer, Area the physical size (ha) of the farm; $N G E$ the economic size of the farm expressed in Dutch size units, which are closely related to a farm's gross margin; PrevExp a Boolean variable for having expanded by more than 4 ha in the preceding 10 year period, and Dairy a Boolean variable for being a dairy farmer or not. Note that $\mathrm{P}$ (behaviour $=4=$ stable) follows automatically from 1 -the sum of the other probabilities. See the online supplement for details about how the four categories were defined, further specifications of the calibration dataset, and the performance of the regression model.

Behaviour by nature-organization agents and estate-owner agents

We assume that nature organization agents and estate agents are expanders. That is, they only buy land and do not sell land. In reality, nature organizations sell land occasionally, but this usually involves recently purchased agricultural land that is traded with farmers for parcels with a higher potential nature value. The net result of this process is that nature organizations behave only as expanders, aiming to buy those parcels with the highest potential nature value. The degree to which nature organizations expand is determined by a combination of purchasing power and their desire to buy land (see next section). 
Parcel evaluation

Shrinking agents (by definition, farmer agents) choose which parcels they want to sell. We assume that they start by selling their least favourable parcels. The parcel appreciation, reflected in the willingness to accept $\left(\mathrm{WTA}_{\mathrm{F}}\right)$ is a function of parcel properties such as agricultural soil suitability and distance to the NEN, but also of the distance between the parcel and the farmstead. Expanding farmer agents use the same parcel evaluation function to estimate their willingness to pay $\left(\mathrm{WTP}_{\mathrm{F}}\right)$ for the parcels in the market. Conversely, nature organization agents have other criteria than farmers when determining their WTP, i.e. the $\mathrm{WTP}_{\mathrm{N}}$, which are related to the potential for successful nature restoration. Expanding private estates evaluate parcels solely from the distance to an existing property.

Statistical analysis resulted in the following equations for WTP (see online supplement for details):

For farmers:

$$
\begin{aligned}
\text { WTP }_{F}= & \text { TTA }_{F} \\
= & (4.16 E-05-1.89 E-07 * \text { SoilSuit } \\
& -1.62 E-03 *(1 /(\text { DistTown }+100)) \\
& +5.26 E-04 *(1 /(\text { DistNEN }+100)))^{-1} \\
& -16.85 *(\text { DistFarmstead }-250)\left(\text { Eha }^{1}\right)
\end{aligned}
$$

where DistFarmstead is the distance between the parcel and the farmstead of the (potential) owner (m), SoilSuit is an indicator for the percentage of the potential yield that can be obtained on the soil in percentage point, DistTown is the distance from the parcel to the nearest town (m), and DistNEN is the distance between the parcel and the NEN (m).

For nature organizations:

$$
\begin{aligned}
W T P_{N}= & \text { Intercept }-7.9 * \text { Distance }+9214 \\
& * \text { Seepage }-320 * G V G\left(€ h a^{-1}\right)
\end{aligned}
$$

where Distance is the distance to the nearest existing nature reserve, Seepage is a dummy variable that indicates the presence of exfiltrating groundwater, and $G V G$ is the groundwater level in cm from surface. The intercept is fine-tuned in "Fine tuning and verifying the model" section.
For estate owners:

$$
\begin{array}{r}
W T P_{E}=35,000 \Theta h a^{-1} \text { if parcelborders existing property } \\
W T P_{E}=0 \Theta h a^{-1} \text { foranyotherparcel }
\end{array}
$$

Simulations

The RULEX schedule runs as follows: at each time step, each farmer agent is assigned one of the four possible behaviours (expanding, shrinking, intensifying/innovating, or stable). This happens by sampling from the probability distribution described by Eqs. 14. As this is a stochastic process, behaviours of a single agent may vary during the course of a model run. Furthermore, behaviour may change over time, as farmer agents grow older, their specific farming type is affected by price changes (see "Relative competitiveness of farming types" section), and their farms expand or shrink because of previous actions.

Each shrinking agent selects the least favoured parcels to sell. By default, the number of parcels that a farmer agent will sell per year is set to one (this model parameter is explored in "Fine tuning and verifying the model" section). Next, each expanding agent (farmers as well as nature organizations and estate owners) evaluates the parcels that are available for sale. If the WTP of the expanding agent is greater than the WTA of the shrinking agent, the parcel changes owner, provided that the WTP exceeds the minimum market price of $17,000 € \mathrm{ha}^{-1}$ (see online supplement). When two expanding agents are interested in the same parcel, it is purchased by the agent with the highest WTP. In RULEX, nature organizations can buy as many desirable parcels as their annual budget permits. For individual farmer agents we did not consider budget limits, as information about capital and savings were not available. Instead, the area a farmer agent can buy per year is limited to one-third of the farm size at that moment in time (see online supplement), and we assume that each expanding farmer agent will find the financial means to buy these parcels.

Not all for-sale parcels change owner in a simulation run: those that are not considered attractive enough for any of the expanding agents remain unsold. Likewise, not all expanding agents are likely to succeed in finding 
a parcel that they want to buy (i.e., that they value higher than the current owner or higher than the minimum market price). The attributes of farmer agents that exchange land are updated accordingly. Physical size is updated by adding or subtracting the area of the bought or sold parcels and economic size is updated by the same ratio as the physical size. The economic size of farmer agents assigned the behaviour intensifying/innovating increases by 0.19 at each time step (see online supplement). Finally, for all farmer agents, age is updated and economic size is updated by applying a farming-type specific annual trend reflecting changes in the market (see next section). Parcels that are sold to a nature organization, estate owner, or to a farmer agent with another farming type change land use.

\section{Relative competitiveness of farming types}

The relative competitiveness of one farming type over another is influenced by the changes in agricultural prices that affect gross margins. This is incorporated into RULEX by specifying a type-specific trend in gross margins, which is imposed on the economic size of each individual farmer (the measure of economic farm size, NGE, is roughly proportional to gross margins). As economic farm size affects the behaviour probability (Eqs. 1-4), these trends in turn, affect the individual farmer agents' decision-making. By imposing a trend per type (on top of the changes for individual farmers as a result of land exchange), a relative change in the competitiveness of one type compared to another can be simulated.

From empirical data, we arrived at the following annual NGE trends for the period 2001-2009: Dairy $1.0 \%$; Arable $+1.4 \%$; Horticulture $-0.4 \%$; Pigbreeding $0.7 \%$; and Mixed $0.2 \%$ (see online supplement for details).

Retirement, succession, and death of farmer agents

As farmer agents become older, many reach the retirement age (65) within a simulation run, and several die. When an agent reaches the retirement age, it either continues ageing or its age is reset to a value normally distributed around 30 with a variance of 16 , to simulate farm succession. Whether or not this happens depends on the economic size of the farm at that time step. Farms with a size less than 8.2 NGE are assumed to have no successor while larger farms do have a successor. The threshold was chosen so that $34 \%$ of all current farmers in the area are smaller, which agrees with national succession rates (de Bont and van Everdingen 2010). The correlation between succession and economic size is confirmed by de Bont and van Everdingen (2010) as well as by individual farmers from the area. Thus, succession was derived indirectly from age and economic farm size.

Farmer agents with a farm that is smaller than this threshold by the time they reach the retirement age remain in business. Since the chance of being a shrinking farmer increases with age (Eqs. 1-4), their dominant behaviour is to sell land. When a farmer agent dies succession is modelled by resetting its age (as above). The death of a farmer agent is determined by the probability of dying from the 2009 WHO Life expectancy table for the Netherlands.

\section{Fine tuning and verifying the model}

Fine tuning the model

While RULEX parameters are empirically-derived, some were difficult to estimate because of a lack of data. This concerned the number of parcels a seller agent puts on the market each year (by default set to 1) and the intercept of the $\mathrm{WTP}_{\mathrm{N}}$ equation (reflecting the combined effect of purchasing power and desire to expand; by default set to 13,000). To assess these parameters, RULEX was run for the period 2001-2009 with varying parameter settings, and the outcomes evaluated using two metrics: (a) the number of transactions for the entire period between farmers (around 500 according to the Infogroma database); (b) the number of transactions for the entire period between farmers and nature organizations (around 18 according to the Infogroma database). We ran each configuration for batches of 10 simulation runs.

Figure 3 shows that the number of transactions between farmers barely responds to the $\mathrm{WTP}_{\mathrm{N}}$ intercept, while it increases in response to an increase in number of parcels to sell. Setting a value of 2 for number of parcels to sell resulted in around 550 exchange transactions, which is close to the observed number of 500 transactions. The number of transactions between farmers and nature organizations (Fig. 4) responds to both variables. Given that the 


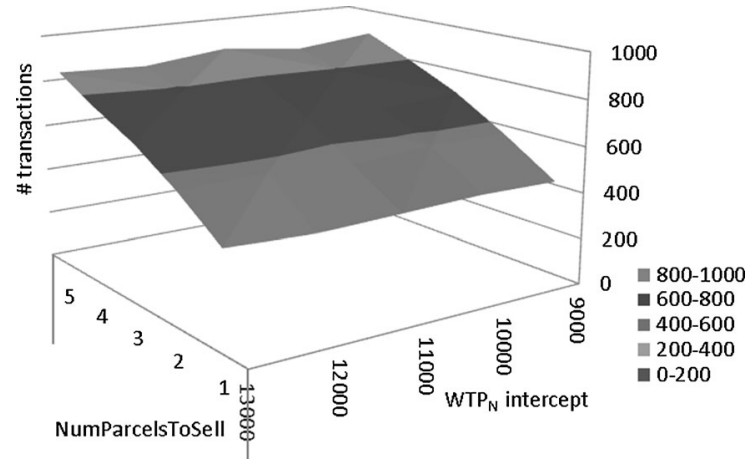

Fig. 3 Response of number of exchange transactions between farmers to the number of parcels to sell and the $\mathrm{WTP}_{\mathrm{N}}$ intercept; averaged over 10 simulation runs per parameter setting

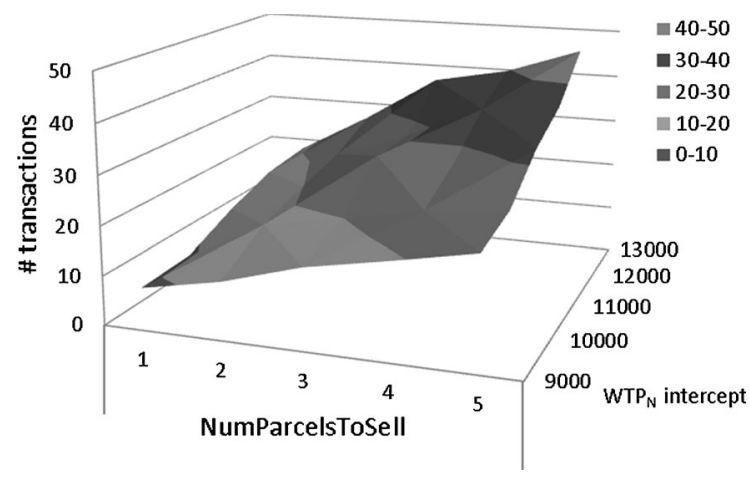

Fig. 4 Response of number of exchange transactions between farmers and nature organizations to the number of parcels to sell and the $\mathrm{WTP}_{\mathrm{N}}$ intercept; averaged over 10 simulation runs per parameter setting

number of parcels to sell was assigned a value of 2 , the best values were achieved with a $\mathrm{WTP}_{\mathrm{N}}$ intercept of 11,000 (20 transactions; observed $=18$ ).

Historical validation of RULEX (2001-2009)

RULEX was run 100 times, using the above-adjusted settings, in order to evaluate its performance for the period 2001-2009. For each run, we computed the simulated change for each land-use type between 2001 and 2009 in hectares and divided that by the total area (Table 4). Being a stochastic model, RULEX can produce innumerable realizations of change trajectories, reflecting real-world volatility. Similarly, the observed state in 2009 was also one of the innumerable realities that could have resulted from the situation in 2001. Whenever this particular realization (i.e. the observed situation in 2009) fell within the range of
Table 3 Observed and simulated trends in the main land-use types between 2001-2009

\begin{tabular}{lccl}
\hline $\begin{array}{l}\text { Farming } \\
\text { type }\end{array}$ & $\begin{array}{l}\text { Observed } \\
\text { trend }(\%)\end{array}$ & $\begin{array}{l}\text { Simulated } \\
\text { trend }(\%)\end{array}$ & $\begin{array}{l}\text { Observation } \\
\text { falls within the } \\
\text { simulated range }\end{array}$ \\
\hline Dairy & -3.1 & 0.2 to 2.2 & No \\
Arable & 2.9 & -1.2 to -0.5 & No \\
Horticulture & 0.5 & -0.3 to 0.1 & No \\
Pig-breeding & -0.6 & -1.1 to -0.2 & Yes \\
Mixed & -1.0 & -2.0 to -0.3 & Yes \\
Estates & 0.9 & 0.5 to 1.1 & Yes \\
Nature & 0.5 & 0.4 to 1.1 & Yes \\
\hline
\end{tabular}

Both observed and simulated trends are given in $\%$ area change in 2009 compared to the baseline situation in 2001

simulated realizations, we considered RULEX to have produced results that were consistent with the observational data.

Table 3 shows that RULEX was able to reproduce observed trends in pig-breeding, mixed farming, and the expansion of estates and nature areas. Trends in dairy farming, arable farming, and horticulture, however, were less well reproduced. For dairy farming, the simulations resulted in a small increase whereas a decrease occurred in the observational data. For arable farming, the simulations resulted in a decline while an increase occurred in the observational data. For horticulture, RULEX simulations showed little or no change, but an increase occurred in the observational data.

In order to evaluate in more detail which conversions were simulated correctly and which were not, we computed the difference between the observed change (in hectares) and the simulated change (average of 100 simulations, in hectares) for each specific conversion from land use $i$ to land use $j$. We expressed these differences as fractions of the total area in the base year 2001, which are shown in Table 4. Deviations of more than $1 \%$ of the area are shown in bold.

Table 4 shows that RULEX tends to overestimate the persistence of dairying, pig-breeding, and mixed farming. In practice, land used for dairying in 2001 was more often used for arable or mixed farming in 2009. Land used for mixed farming in 2001 was more often used for arable farming or dairying in 2009. This may be because RULEX only simulates land-use change resulting from land exchange, while observed 
Table 4 Deviations between simulated and observed conversions as a percentage of the total area of a land use type in 2001 ( $i$ )

\begin{tabular}{|c|c|c|c|c|c|c|c|}
\hline \multirow[t]{2}{*}{$2001(i)$} & \multicolumn{7}{|c|}{$2009(j)$} \\
\hline & Arable & Dairy & Horticulture & Mixed & Pig-breeding & Nature & Estates \\
\hline Arable & 0.6 & 0.3 & 0.0 & -0.1 & -0.1 & 0.0 & 0.0 \\
\hline Dairy & -1.6 & 18.9 & -0.4 & -3.7 & -0.3 & 0.1 & 0.0 \\
\hline Horticulture & -0.1 & 0.0 & 0.2 & 0.0 & 0.0 & 0.0 & 0.0 \\
\hline Mixed & -1.0 & -2.3 & -0.1 & 5.3 & -0.5 & 0.2 & 0.1 \\
\hline Pig-breeding & -0.5 & -0.1 & 0.0 & -0.3 & 2.3 & 0.0 & 0.0 \\
\hline
\end{tabular}

Entries in the table are computed as [ conversion $_{i, j}(\operatorname{simulated})$-conversion $_{i, j}($ observed $\left.)\right] /$ total area $_{i}$

Table 5 Contingency table of farming type per farm between 1999 and 2009

\begin{tabular}{lccccc}
\hline $1999(i)$ & \multicolumn{2}{l}{$2009(j)$} & & & \\
\cline { 2 - 6 } & Arable & Dairy & Horticulture & Mixed & Pig-breeding \\
\hline Arable & 14 & 1 & 0 & 3 & 1 \\
Dairy & $\mathbf{1 5}$ & 480 & 4 & $\mathbf{3 7}$ & 1 \\
Horticulture & 0 & 2 & 10 & 1 & 0 \\
Mixed & $\mathbf{1 5}$ & $\mathbf{3 5}$ & 3 & 27 & 5 \\
Pig-breeding & 8 & 12 & 2 & 12 & 52 \\
\hline
\end{tabular}

land-use change may also result from farmers changing from one farming type to another. This is confirmed by a contingency table of all farms that were in the panel database used for the regression analysis in "Behaviour of farmer agents" section. Although the panel data cover another period (1999-2009), these numbers were taken to approximate trends for the study period (2001-2009). Table 5 shows that several farms did indeed change from one farming type to another. Bold-printed conversion numbers in Table 5 correspond to conversions for which Table 4 shows a high deviation (not taking account of farmers who persisted in their farming type).

A more detailed investigation of these farms in the agricultural census revealed the following: farms that were classified as 'mixed' in 1999 and as 'arable' or 'dairy' in 2009 mostly concerned shrinking mixed farms that ceased one of their activities. By doing so, these farms turned from being a mixed farm into an arable or dairy farm. The change from dairy farms to arable farms mostly involved small and shrinking dairy farmers, who sold their cows and their grassland, but retained arable land (most dairy farmers have a few arable fields for fodder production) on which they continued to produce fodder crops. Within the RULEX context, these are shrinking dairy farmers, but in the agricultural census, they were classified as arable farmers. A similar case concerns the land used for dairying in 1999 and for mixed farming in 2009 in which dairy farmers sold cows and grassland, and hence shifted to the category mixed.

Finally, a spatially-explicit model performance assessment was made by overlaying simulated and observed land use maps. Because RULEX outputs vary stochastically, we selected a single model run that we considered to be representative of all model runs. This was done by computing for each parcel the mode of 100 simulations, and then computing for each simulation the deviation from this mode. The simulation with the smallest deviation from the mode was considered to be the most representative simulation (Fig. s6 in the online supplement). The overlay is shown in the online supplement (Fig. s7), and here we show the area classified as Hits (of which some are wrong hits), Misses, False Alarms and Correct Rejections in tabular form (Table 6).

Of the area that underwent change, $58 \%$ was simulated to undergo change. When we also require that the target land use category is correctly simulated, this reduces to $26 \%$. Of the area that remained unchanged, $77 \%$ was also simulated to remain unchanged. In total, correct simulations (whether this concerned change or persistence) occurred over 
Table 6 Spatially-explicit model performance

\begin{tabular}{lll}
\hline & Hectares & Correctly predicted \\
\hline Hits & 1,318 & Change: $58 \%$ \\
& (of which 724 & $\begin{array}{c}\text { (26\% when } \\
\text { excluding }\end{array}$ \\
Misses & 955 & wrong hits) \\
False alarms & 2,153 & Persistence: $77 \%$ \\
Correct rejections & 7,083 & \\
\hline
\end{tabular}

8,401 ha, or $73 \%$ of the total area. When we also require the target land use category to be correctly simulated, this number becomes 7,677 ha, or $67 \%$.

\section{Discussion}

The results show that RULEX is able to reproduce historic land-use-change trends in the Baakse Beek region, although it tends to overestimate the persistence of dairying, arable farming and pig-breeding. This is partly because RULEX only simulates one mechanism of land-use change, through land exchange, with farmers deciding to change farming type not being simulated. However, because farms in the census data are classified into one farming type category, a small change in management or animal numbers may result in what is perceived to be a landuse change. In particular, the high observed rates of farms changing from dairy to mixed or arable in the census data were often the result of the retirement of farmers leading to sales of cows and some grassland, and the retention of some arable fields to continue growing fodder crops. This was similar for farms changing from mixed to arable or dairy: in most cases this arose from the loss of one of these activities leading to a classification change.

The RULEX model is stochastic since the farmer agent behaviour is sampled from a probability distribution, which is computed for each farm at each time step. Farmer-agent behaviour, and model outcome, are therefore dependent on the fit of the regression models as described in Eqs. 1-4. The computed McFadden's $\mathrm{R}^{2}$ for these models was 0.16 . Although this can be considered a relatively good fit for these types of data (for comparison, Cotteleer et al. (2008) found an $\mathrm{R}^{2}$ value of 0.04 when distinguishing buyer-farmers (in one year) from non-buying farmers, based on many more independent variables), a large part of the observed farmer behaviour still remains unaccounted for, which adds uncertainty to the model outcomes. This uncertainty increases further because land exchange between farmers depends on the simulated behaviour of two agents and the behaviour in a certain year is partly dependent on the behaviour in previous years. However, the simulated ranges presented in Table 3 suggest that although uncertainties accumulate during a simulation run, the large number of agents within the model and the multiple simulation years leads to a partial cancellation of random errors. This indicates that despite uncertainty at the micro level, simulated land-use change at the macro level is relatively stable.

From a modelling point-of-view, all empirical (agent-based) models are data hungry, often requiring multiple types of qualitative and quantitative data inputs. Gathering and processing social and spatial data for detailed case studies is a labour intensive task, which is why there are only a few descriptive and datadriven ABMs. A prominent feature of the RULEX model is the systematic use of real data (such as maps, census, and semi-structured interviews) for a real landscape and the simulation of a bidding process that occurs in reality rather than for a hypothetical space. Moving away from the more prevalent 'theoretical' approaches found in most ABMs of land markets, RULEX explores land exchange processes that are calibrated and validated against real data. This is beneficial as it allows for open cross-validation of the model as well as the exploration of land-use-change futures under various climate and socio-economic change scenarios (e.g. Murray-Rust et al. 2013), making RULEX a potentially powerful policy analysis tool. Before such explorations can be made, a sensitivity analysis of RULEX to a range of model parameters and input variables is needed, which will be the topic of a forthcoming paper. Furthermore, a structural validation could further help to identify the model's limitations, which would provide a basis for a new cycle of model improvement (Brown et al. 2013a, b). The land exchange mechanism could, for instance, be combined with mechanisms simulating the change of farming type within one agent. This would require that tendencies to change farming type are related to the farm(er) properties as was done for tendencies to sell or buy land. Examples of such exercises can be found in (Guillem et al. 2012; Karali et al. 2013a, b). 
The strong empirical grounding of the model had the additional advantage of supporting communication of the model results to stakeholders (farmers, farmer union representatives, provincial policy makers, nature organizations, and estate holders from within the area). During various meetings and workshops, stakeholders indicated that they recognized the simulated processes and thought the model to be a good representation of the case study, albeit a simplification of reality. Farmers indicated that they could identify with the simulated farmer agents. It is also interesting to note that stakeholders found the stochastic nature of RULEX to contribute positively to its plausibility. Farmers recognized in particular the real-world uncertainty associated with decisions about expanding and having to speculate on which parcels will become available for sale in the near future. Policymakers found the stochastic outcomes to be useful in identifying areas within the Baakse Beek that were stable or where the same transactions always occurred (i.e. where intervention was pointless) and which were more uncertain (i.e. where policy measures to steer a particular land use change are likely to be effective).

An important disadvantage of the empiricallygrounded approach is the limited flexibility provided by the regression-based decision rules. Although a linear regression with uncorrelated independent variables would allow experimentation with the role of one or more of these variables by adjusting the regression coefficients, this becomes complicated in the case of the non-linear regressions that were used to identify farmer behaviour and farmers' willingness to pay for parcels. Also, new behaviours or new decisioncriteria are difficult to incorporate. Conversely, the part of RULEX that simulates land exchange is independent of the structure and coefficients in Eqs. 1-7, so theoretically, these equations could be substituted with equations derived from other sources.

\section{Conclusions}

In this paper we present an agent-based model that simulates the process of land exchange between different types of land owners as a driver of land-use change. In areas where pressure on land is high and land-use change is to a considerable extent brought about by land exchange, land-exchange mechanisms are important to account for. However, land exchange is not the only process causing land-use change, and a more comprehensive model should account for other land-use change processes as well.

The pertinence of the processes simulated by RULEX was corroborated by stakeholders from within the study area. This refers to both the micro level processes (e.g. farmers' land selling and buying strategy) and macro level processes (e.g. policy makers recognizing the modelled processes). This suggests that RULEX could be a useful instrument for participatory scenario explorations of, for example, simulations of land-use change in response to drivers such as price changes and changes in soil quality. In addition, RULEX can be used as a laboratory to explore policy options, such as the effect of subsidies on land purchases or zoning policies to achieve nature targets.

Acknowledgments We would like to thank Tom Kuhlman for his help with retrieving and interpreting data from the agricultural census and the Infogroma database. This work was carried out within the project Climate Adaptation for Rural Areas (CARE), which was funded by the Knowledge for Climate Programme (http://knowledgeforclimate.climateresearch netherlands.nl/climateadaptationforruralareas).

Open Access This article is distributed under the terms of the Creative Commons Attribution License which permits any use, distribution, and reproduction in any medium, provided the original author(s) and the source are credited.

\section{References}

Alam SJ, Bakker MM, Karali E, van Dijk J, Rounsevell MDA (2014) Simulating the expansion of large-sized farms in rural Netherlands: a land exchange model. In: Alam SJ, Parunak HVD (eds) Multi-agent-based simulation XIV. Springer, New York

Alexander P, Moran D, Rounsevell MDA, Smith P (2013) Modelling the perennial energy crop market: the role of spatial diffusion. J R Soc Interface 10(88):20130656

Berger T (2001) Agent-based spatial models applied to agriculture: a simulation tool for technology diffusion, resource use changes and policy analysis. Agric Econ 25(2-3):245-260

Bousquet F, Le Page C (2004) Multi-agent simulations and ecosystem management: a review. Ecol Model 76(3-4):131-332

Brown DG, Robinson DT, An L, Nassauer JI, Zellner M, Rand W, Riolo R, Page SE, Low B, Wang Z (2008) Exurbia from the bottom-up: confronting empirical challenges to characterizing a complex system. Geoforum 39(2):805-818 
Brown DG, Band LE, Green KO, Irwin E, Jain A, Lambin EF, Pontius RG Jr, Seto KC, Turner Ii BL, Verburg PH (2013a) Advancing land change modeling: opportunities and research requirements. The National Academies Press, Washington DC

Brown DG, Verburg PH, Pontius RG, Lange MD (2013b) Opportunities to improve impact, integration, and evaluation of land change models. Curr Opin Environ Sustain 5(5):452-457

Cotteleer G, Gardebroek C, Luijt J (2008) Market power in a GIS-based hedonic price model of local farmland markets. Land Econ 84(4):573-592

de Bont K, van Everdingen W (2010) Vooral veel kleine bedrijven zonder opvolger, agri-monitor. Agricultural Economics Institute, Wageningen University and Research Centre, The Hague

Government Service for Land and Water Management (Dienst Regelingen) (2012). Agricultural census of 2009, Hague

Filatova T, Voinov A, van der Veen A (2011) Land market mechanisms for preservation of space for coastal ecosystems: an agent-based analysis. Environ Model Softw 26(2):179-190

Geller A, Moss S (2008) Growing qawm: an evidence-driven declarative model of Afghan power structures. Adv Complex Syst 11(2):321-335

Grimm V, Berger U, Bastiansen F, Eliassen S, Ginot V, Giske J, Goss-Custard J, Grand T, Heinz SK, Huse G, Huth A, Jepsen JU, Jørgensen C, Mooij WM, Müller B, Pe'er G, Piou C, Railsback SF, Robbins AM, Robbins MM, Rossmanith E, Rüger N, Strand E, Souissi S, Stillman RA, Vabø R, Visser U, DeAngelis DL (2006) A standard protocol for describing individual-based and agent-based models. Ecol Model 198(1-2):115-126

Guillem EE, Barnes AP, Rounsevell MDA, Renwick A (2012) Refining perception-based farmer typologies with the analysis of past census data. J Environ Manage 110:226-235

Hilferink M, Rietveld P (1998) Land use scanner. Tinbergen Institute, Amsterdam

Huang Q, Parker DC, Filatova T, Sun S (2013) A review of urban residential choice models using agent-based modeling. Environ Plan B 40 41(4):661-689. doi:10.1068/ b120043

Karali E, Rounsevell MDA, Doherty R (2011) Integrating the diversity of farmers' decisions into studies of rural land-use change. Procedia Environ Sci 6:136-145

Karali E, Brunner B, Doherty R, Hersperger AM, Rounsevell MDA (2013a) The effect of farmer attitudes and objectives on the heterogeneity of farm attributes and management in Switzerland. Hum Ecol 41(6):915-926

Karali E, Brunner B, Doherty R, Hersperger AM, Rounsevell MDA (2013b) Identifying the factors that influence farmer participation in environmental management practices in Switzerland. Hum Ecol. doi:10.1007/s10745-014-9701-5
Kelley H, Evans T (2011) The relative influences of land-owner and landscape heterogeneity in an agent-based model of land-use. Ecol Econ 70(6):1075-1087

Lokhorst AM, Van Dijk J, Staats H, Van Dijk E, De Snoo G (2010) Using tailored information and public commitment to improve the environmental quality of farm lands: an example from the Netherlands. Hum Ecol 38:113-122

Lokhorst AM, Staats H, Van Dijk J, Van Dijk E, De Snoo G (2011) What's in it for me? Motivational differences between farmers' subsidised and non-subsidised conservation practices. Appl Physchology 60(3):337-353

Macmillan W, Huang HQ (2008) An agent-based simulation model of a primitive agricultural society. Geoforum 39(2):643-658

Matthews RB, Gilbert NG, Roach A, Polhill JG, Gotts NM (2007) Agent-based land-use models: a review of applications. Landscape Ecol 22(10):1447-1459

Murray-Rust D, Rieser V, Robinson DT, Milicic V, Rounsevell MDA., 2013. Agent-based modelling of land use dynamics and residential quality of life for future scenarios . Environ Model Softw 46:75-89

Parker DC, Hessl A, Davis SC (2008) Complexity, land-use modeling, and the human dimension: fundamental challenges for mapping unknown outcome spaces. Geoforum 39:789-804

Polhill JG, Gimona A, Aspinall RJ (2011) Agent-based modelling of land use effects on ecosystem processes and services. J Land Use Sci 6(2-3):75-81

Rounsevell MDA, Annetts JE, Audsley E, Mayr T, Reginster I (2003) Modelling the spatial distribution of agricultural land use at the regional scale. Agric Ecosyst Environ 95:465-479

Schouten M, Opdam P, Polman N, Westerhof E (2013) Resilience-based governance in rural landscapes: experiments with agri-environment schemes using a spatially explicit agent-based model. Land Use Policy 30(1):934-943

Valbuena D, Verburg PH, Bregt AK, Ligtenberg A (2010) An agent-based approach to model land-use change at a regional scale. Landscape Ecol 25(2):185-199

van Ittersum MK, Ewert F, Heckelei T, Wery J, Alkan Olsson J, Andersen E, Bezlepkina I, Brouwer F, Donatelli M, Flichman G, Olsson L, Rizzoli AE, van der Wal T, Wien JE, Wolf J (2008) Integrated assessment of agricultural systems-A component-based framework for the European Union (SEAMLESS). Agric Syst 96(1-3):150-165

Verburg PH, Overmars KP (2009) Combining top-down and bottom-up dynamics in land use modeling: exploring the future of abandoned farmlands in Europe with the DynaCLUE model. Landscape Ecol 24(9):1167-1181

Xie Y, Batty M, Zhao K (2007) Simulating emergent urban form using agent-based modeling: Desakota in the SuzhouWuxian Region in China. Ann Assoc Am Geogr 97(3):477-495 